ISSN: 0213-2079 - ISSN electrónico: 2386-3889

DOI: https://doi.org/10.14201/shhmo20204221319

\title{
DEL MEDITERRÁNEO AL ATLÁNTICO. MERCADERES EN LAS URBES (SIGLOS XVI-XVII)
}

De la Méditerranée à l'Atlantique. Des marchands dans la ville (XVI-XVII siècle)

\section{PRESENTACIÓN ${ }^{1}$}

\section{Presentation}

José Jaime GARCÍA BERNAL

Araceli GUILLAUME-ALONSO

Béatrice PEREZ

Maria ZERARI

Ser uno mercader es dignidad Mateo Alemán, Guzmán de Alfarache, II.

Il faut être marchand ou larron

Refrán.

Un tema integrador y amplio, El mercader. Perfiles (Le marchand. Variété des figures) vincula desde hace años a los modernistas parisinos de CLEA (EA 4083) y

1. Este trabajo se enmarca en el Proyecto de $\mathrm{I}+\mathrm{D}+\mathrm{i}$ «La construcción de un mundo nuevo: circuitos económicos, dinámicas sociales y mediadores culturales en las ciudades atlánticas del sur de España, siglos XVI-XVIII» (HAR2017-85305-P), así como en el Proyecto I+D+i FEDER Andalucía «En torno a la Primera Globalización: circulaciones y conexiones entre el Atlántico y el Mediterráneo (1492-1824)» (US-1262566). 
a los historiadores sevillanos de ANDATLAN (I+D financiado por el Ministerio de Economía y Competitividad) en la tarea colectiva de reconstituir el negocio y la figura compleja del mercader, castellano, flamenco, genovés, banquero, contable, armador, oligarca o mayordomo al servicio de las élites eclesiásticas, noble, mecenas $\mathrm{u}$ hombre de letras ocasional. En el curso de las investigaciones de miembros integrantes de CLEA (Béatrice Perez) y tratando de acotar la percepción que la sociedad tuvo del mercader, nos fuimos dando cuenta de su extrema variabilidad. El mercader aparece a veces como un humanista obrando por el bien de la Respublica al fomentar intercambios entre «naciones» ${ }^{2}$ y otras como un hombre codicioso y adepto de Mammón, que no puede evitar perjurar ni engañar a su prójimo. Obviamente, trabajar sobre la figura del mercader requiere una periodización ajustada para definir con precisión la inserción de este último en la sociedad. Del mercader (examinado a la luz de su cultura, su formación, sus libros de cuentas y los útiles que instaura) hasta la sociedad misma (a través de la mirada que ella dirige a la comunidad mercantil, ya sea reprobadora respecto a las técnicas de cambio, ya elogiosa ante la utilidad social del arte de la mercadería), la reflexión moviliza temáticas variadas.

Figura social extensamente glosada y puesta de relieve en las causas judiciales, los tratados políticos y los discursos de la España de los años 1520-1620, el mercader es, por antonomasia, ese hombre del medio urbano tradicionalmente desprestigiado por la ideología nobiliaria y por el pensamiento cristiano (proceso a la usura, la codicia y el dinero) aun siendo su propio fermento.

Mercaderes en las urbes / Des marchands dans la ville. La idea primordial va enunciada en el título y expresa la voluntad de los autores por entender mejor el papel social del mercader, su inserción en un mundo que ha dejado de ser el de la mercancía, pero que implica que el que goza de riqueza y poder se adueñe de los códigos y costumbres de las sociedades urbanas y de los círculos nobiliarios para imponerse más y mejor. Después, este dossier aspira a dar un giro hacia el Mediterráneo, o al menos, a anudar en una misma comprensión intelectual el continuum histórico del Mediterráneo al Atlántico. En efecto, los modernistas de CLEA y los historiadores sevillanos de ANDATLAN trabajan sobre problemáticas que ponen en relación el tema mercantil con los horizontes transatlánticos. No hay duda de que en la Sevilla efervescente del siglo XVI la perspectiva americana propició una multiplicidad de actitudes nuevas, de expresiones novedosas (tales como mercader a Indias, cargador a Indias, Indiano), de instituciones emergentes (Casa de Contratación, Audiencia Indiana, Consulado de la Universidad de mercaderes) y, en definitiva, de retratos cristalizados, coherentes e imperecederos. Sin embargo, ese tropismo americano no debe ocultar la gran variedad de mercaderes que surcaron el Mediterráneo -central

2. El término «nación» se emplea en el sentido que le concede la sociedad del siglo XVI, esto es, comunidades extranjeras que tenían derecho de ciudadanía en la urbe. 
en el siglo XVII-, a menudo arrumbados en un ángulo muerto de la investigación en beneficio precisamente de los nuevos espacios atlánticos. Tenemos la íntima convicción de que la primera mundialización, la de las circulaciones marítimas, no puede concebirse sin esta conjunción de espacios mediterráneo, atlántico y pacífico que obliga a deconstruir la percepción eurocéntrica para entender mejor aquel mundo conectado donde los movimientos en sinergia (de hombres, barcos, mercancías y técnicas) dejan entrever vastas extensiones perfectamente dominadas.

Así, de las islas Baleares a África, de Valencia al sur de Italia y las islas griegas, de Málaga a Sicilia y los puertos de la costa magrebí, ¿ pusieron en juego los intercambios comerciales los mismos prerrequisitos que condicionaron al mercader atlántico? Las cualidades para comerciar entre esas dos zonas fronterizas que se conectan, esos dos mundos que se observan, se espían, se enardecen y apaciguan a merced de los conflictos armados y de los tiempos de paz en el Mediterráneo ¿son las mismas? Observar a los mercaderes de Venecia, Valencia, Málaga o Cádiz orientando el mercado hacia el aprovisionamiento de las tierras de la costa africana y los negocios hacia los países tradicionales del comercio europeo -donde productos como el pastel del sur de Francia, el trigo de Sicilia o las especies del Oriente, son de permanente rentabilidad- permite mantener vuelta la mirada a Italia y a la Europa mediterránea para concebir mejor los flujos mercantiles hacia un mundo americano cada vez más imponente.

La segunda idea que estructura este dossier se refiere a la inserción del mercader en la sociedad urbana. Hemos querido examinarla tanto desde unos criterios endógenos (su formación, sus competencias, sus representaciones en los diferentes actos y celebraciones que acompasan la vida cotidiana de la ciudad) como desde un ángulo exógeno (atento a su integración espacio-profesional y urbana). Este doble punto de vista permite definirlo como un actor económico de primer plano (a través de sus empresas «multirriesgo», sus inversiones en operaciones financieras de alto riesgo y máximo rendimiento, por rutas mercantiles rentables por inciertas), pero también y sobre todo como un actor social clave de su tiempo.

No se puede pasar por alto su papel en y sobre la sociedad que le rodea, a riesgo de percibir solo la faceta más convencional de su definición: la relativa a sus actividades financieras. El mercader se impregna del espíritu de los tiempos, de las modas, de las maneras de ser y de hacer de la sociedad aristocrática, la cual violenta para integrarse mejor en ella-financieramente primero, socialmente después. El comerciante la modela de este modo, en tanto que es modelado por ella; una sociedad en la que juega, de hecho, por su peso financiero, un papel esencial. Sus inversiones son desde luego mercantiles, pero más allá de la inmanencia de la ganancia, lo que está fundamentalmente en juego es su asimilación pura y simple a las plutocracias locales. Cuando el mercader americano Hernando Gorjón lucha durante toda su vida para obtener el hábito de Santiago, pagando generosamente a diversos fiscales 
para alcanzar sus fines, no ambiciona otra cosa que el reconocimiento social pleno y definitivo de un estado de cosas: el brillo de su rango en la jerarquía local (Rodríguez Morel, 1995). En este sentido hay que entender que emprenda la fundación de un hospital y de una universidad para acoger pobres de forma gratuita, como otras tantas manifestaciones tangibles de su compromiso social (en concreto, de su caridad). Del mismo modo hay que entender la inversión de los mercaderes de la familia Alcázar, convertidos en financieros de Carlos V, en la compra de tierras y la constitución de cuatro mayorazgos en beneficio de los cuatro herederos de la casa (Herrera García, 1981).

El mercader, por poco que lo consideremos en su entramado social, plantea crudamente la cuestión de la promoción social por la riqueza (sea cual sea su procedencia) y el patrimonio acumulado bajo la forma de bienes que actúan como «marcadores sociales». Esos bienes y capitales, materiales y simbólicos, van desde los cargos ostentados, hasta los palacios, los vastos dominios sobre los que ejercen la jurisdicción, en fin, hasta las capillas, las obras de arte, etc. Las formas de mecenazgo mercantil o de inversiones culturales son esenciales para entender los mecanismos de promoción y suponen una idea previa: los mercaderes adoptan con gran rapidez los usos y costumbres de las élites urbanas para asegurarse mejor el acceso a una sociabilidad compartida, sobrepasando así ampliamente el círculo de la mercancía y del análisis reticular.

¿Cómo se incardina el mercader en una Respublica de hombres de bien, de letras y de nobleza a la cual aspira? ¿Qué juegos simbólicos se establecen entre él y esa sociedad urbana? Las escalas de análisis encajan a partir de la visión que tiene el mercader de su propio papel cívico, de la función de su corporación, de su gremio, de su consulado... hasta el rol que la sociedad urbana le asigna-sociedad en la cual se labra, legítimamente, un lugar privilegiado, en la medida en que acumula riqueza, lujo, educación, viajes, esmerado aprendizaje, y otras tantas virtudes que le hacen apto para dominar las oligarquías urbanas. De la dialéctica «sociedad» / «élite mercantil» procede la percepción ética del comercio y de sus mecanismos, de una parte; la aprehensión de aquello que implica la mercancía en la cultura urbana $\mathrm{y}$ las formas variadas del mecenazgo mercantil, de la otra.

En este volumen, los ejemplos son muy variados, planteando de nuevo la multiplicidad de casos emblemáticos y de prototipos de mercader. Juan José Iglesias Rodríguez (Universidad de Sevilla) muestra de qué modo la actividad como cargadores a Indias de los Sopranis genoveses de Cádiz sustenta sus trayectorias políticas en la ciudad portuaria (en cuanto que regidores perpetuos), su extraordinaria devoción mostrada en la fundación de capillas y en las dotaciones piadosas, así como en el lujo fastuoso propio de las élites ostentosas (armas en las fachadas de los palacios, esclavos, obras de arte y otras curiosidades asiáticas). Béatrice Perez (Sorbonne Université), a través del estudio del testamento, de diversos reconocimientos de 
deuda y del inventario post mortem de Juan Marcos Jaqueto, mercader veneciano fallecido en Tlaxcala (Chiapas) en 1603, hace revivir una compañía americana de cacao, sus circuitos monetarios entre el Nuevo Mundo, Valencia y Venecia, y las especificidades de un hombre obsesionado, en el ocaso de su vida, por la salvación de su alma que él busca en las fundaciones piadosas y en las capillas que fundó.

Valencia / Mexico: las ciudades articulan la circulación económica adaptando las técnicas de seguros marítimos, de arrendamiento, de crédito, es decir, las técnicas experimentadas de fraude fiscal. Enrique Cruselles Gómez (Universidad de Valencia) analiza los mercados financieros valencianos y la crisis económica que conoció la ciudad. Él la percibe más como el signo de un estancamiento social, ligado a la consunción del grupo comercial local (acentuado por la persecución inquisitorial de los hombres de negocios de origen converso) que como una recesión del mercado. Esta crisis sería, por otra parte, una consecuencia de la famosa promoción social propiciada por la actividad mercantil que hemos evocado antes. En Valencia los mercaderes se vieron acorralados entre las élites políticas urbanas que monopolizaban los asuntos financieros en provecho propio y un artesanado enriquecido que buscaba sacar provecho de las oportunidades del comercio. La clase mercantil valenciana, atrapada entre esas dos fuerzas, quedó, en consecuencia, debilitada, y progresivamente desclasada.

Guillermina del Valle Pavón (Instituto Mora, México) estudia el comercio de la plata en la ciudad de México, principalmente el negocio ilegal de esta riqueza que se hacía con la complicidad de los propios virreyes. Los circuitos clandestinos -protegidos por las infraestructuras administrativas de la corona y toda una red de complicidades en los puertos (autoridades portuarias y maestros de navíos)- unen las casas de comercio sevillanas y gaditanas a la expansión de los mercados mejicanos. Estos juegos mercantiles entre dos mundos, entre dos modalidades (legal / ilegal) pesaron sobre los flujos, sobre la oferta de mercancías europeas y asiáticas, sobre el establecimiento de los precios y sobre los conflictos entre los intereses peninsulares y los del consulado de Nueva España.

En esta misma cuestión compleja del aprovisionamiento y de la cultura material se centra el artículo de Bernd Hausberger (Colegio de México) que estudia el abastecimiento de las misiones de la Compañía de Jesús en el noroeste de Nueva España. Demuestra el autor hasta qué punto estuvieron implicados los jesuitas en aquella cultura material del consumo que acarreó un flujo considerable de mercancías procedentes del mundo entero, desde el centro del virreinato hasta los confines de las fronteras dominadas. Las misiones jesuitas estuvieron así insertadas de lleno y precozmente en un sistema comercial que articuló diferentes partes del globo.

«Sería difícil definir un mercader que fuera el arquetipo de todos los mercaderes» (Jeannin, 1957). Y dicha definición nos parece aún más condenada al fracaso si no intentamos definir su forma de pensar, de vivir, de expresar su fe, su compromiso 
con las artes y la expresión de la quintaesencia de la perfección de un mundo del que él se siente en todo momento el artífice.

Los numerosos bienes culturales que adquieren los mercaderes muestran que «no tienen el dinero triste» y que más allá de sus firmes compromisos religiosos participan a su modo en el desarrollo de una «secularización de la cultura» (Le Goff, 2001). De las escuelas de ábacos a los métodos de cálculo; el aprendizaje de la geografía (corografía o cartografía); de las lenguas vernáculas al estudio de la historia a mayor gloria de su ciudad y de la monarquía española, el mercader no se concibe fuera de la creación artística. De hecho, el mecenazgo es, sin duda alguna, el más hermoso negocio moderno puesto que el mercader obtiene de él un triple beneficio. En primer lugar, invertir en las artes es siempre muy rentable porque el comercio de las obras de arte (tapicerías, lienzos, joyas, muebles, etc.) se convierte en un elemento esencial de la sociabilidad de corte. En segundo lugar, esta inversión permite a las élites mercantiles materializar, de manera palpable, su riqueza y, por ende, su rango en la jerarquía social. Finalmente, el mecenazgo resulta una operación de captación de poder: al dominar las artes en un escenario urbano que se lee como un gigantesco palimpsesto, las élites mercantiles labran el elogio de la función del homo economicus de los Tiempos modernos. Del caballero cristiano al caballero de las letras, al mercader le gustaría encarnar al arquetipo de la discreción moderna y, en este sentido, la obra artística opera como el vector de una empresa de propaganda hábilmente dirigida y controlada.

Así es como el consulado de cargadores y mercaderes a Indias de Sevilla, fundado en 1543 -con funciones, en principio, judiciales y gremiales, que en seguida se extendieron a las administrativas para convertirse, en palabras de Enriqueta Vila, en un «auténtico banquero de la corona»-, se lanzó a una gran empresa de mecenazgo. Y, sin haber alcanzado aún el cénit de su poder financiero ya exhibió, en 1572, su riqueza y prestigio en las fiestas por la victoria de Lepanto y el nacimiento del príncipe don Fernando, que José Jaime García Bernal (Universidad de Sevilla) analiza en este dossier. Durante los meses de enero y febrero de aquel año, la ciudad y sus principales oficios e instituciones homenajearon a los reyes manifestando en desfiles de máscaras, con carros de triunfo, la lealtad institucional a la corona. La inventiva de que hizo gala el gremio de los madereros le valió el premio de la ciudad, pero no fue menor el ingenio que exhibieron sastres, doradores o curtidores en sus propios espectáculos. Sobresalen en estas fiestas los gremios vinculados al comercio que eran los mayores contribuyentes de las alcabalas sevillanas. La universidad de mercaderes (el consulado) coronó cinco semanas de cortejos con una invención y máscara a la victoria de Lepanto que demuestra la estrecha relación entre el mecenazgo burgués y las novedades escénicas teatral y festiva.

Y el análisis podría extenderse a las artes del lujo denominadas menores, tales como el ornato, el mobiliario y la moda: 
La influencia del mercader es quizá mayor aún en la evolución de las artes menores. Con anterioridad estas artes se lo debían todo a la Iglesia: orfebrería de relicarios y urnas; tejidos valiosos de los ornamentos de la Iglesia y de las ropas eclesiásticas. Ahora, son las joyas, el mobiliario, gloria de la familia burguesa [...] (J. Le Goff, 2001).

La élite mercantil ¿no se convierte acaso -por esta conjunción del poder y de la riqueza ostentada- en el reflejo de una virtus que se percibe en el esplendor de una cultura artística que ella misma ha contribuido a producir? Y en medio de tal desenfreno artístico ¿no intenta crear el mercader el espejismo de encarnar la verdadera nobleza civil, exhibiendo más fasto, más magnificencia y grandeza que las viejas noblezas de sangre?

Todas estas hipótesis requieren, ciertamente, estudios de caso más numerosos para ser confirmadas, matizadas, invalidadas incluso. No obstante, en este volumen, el lector curioso encontrará esbozados los primeros elementos de respuesta a tales interrogantes.

\section{BIBLIOGRAFÍA}

Herrera García, A. (1981). La riqueza de algunos descendientes de conversos: los mayorazgos fundados por el sevillano Francisco del Alcázar. Sefarad, 41.

Jeannin, P. (1957). Les Marchands au XVI e siècle. Paris: Éditions du Seuil.

Le Goff, J. (2001). Le rôle culturel. En J. Le Goff (coord.), Marchands et banquiers du Moyen Âge (pp. 97-122). Paris: Presses Universitaires de France.

Rodríguez Morel, G. (1995). Cartas privadas de Hernando Gorjón, Anuario de estudios americanos, 52(2).

Vila Vilar, E. (2016). El Consulado de Sevilla de Mercaderes a Indias (p. 95). Sevilla: ICAS. 
